\title{
Mycotoxigenic fungi contamination of grains and peanuts from open markets in Kelantan, Malaysia
}

\author{
${ }^{1,2}$ Salisu, B., ${ }^{3, *}$ Anua, S.M., ${ }^{4}$ Wan Ishak, W.R. and ${ }^{5}$ Mazlan, N. \\ ${ }^{1}$ Environmental and Occupational Health Programme, School of Health Sciences, Health Campus, \\ Universiti Sains Malaysia, 16150 Kubang Kerian, Kelantan, Malaysia. \\ ${ }^{2}$ Department of Microbiology, Umaru Musa YarAdua University, PMB 2218, Katsina, Nigeria. \\ ${ }^{3}$ Environmental and Occupational Health Programme, School of Health Sciences, Health Campus \\ Universiti Sains Malaysia, 16150 Kubang Kerian, Kelantan, Malaysia. \\ ${ }^{4}$ Nutrition and Dietetics Programme, School of Health Sciences, Health Campus, Universiti Sains Malaysia, \\ 16150 Kubang Kerian, Kelantan, Malaysia. \\ ${ }^{5}$ Borneo Marine Research Institute, Universiti Malaysia Sabah, Jalan UMS, 88400 Kota Kinabalu, Sabah, \\ Malaysia.
}

\begin{abstract}
Article history:
Received: 10 June 2021

Received in revised form: 14 July 2021

Accepted: 18 October 2021

Available Online: 16 January 2022
\end{abstract}

Keywords:

Bioburden,

Food Grains,

Mycotoxigenic Fungi,

Mycotoxins,

Peanut

DOI:

https://doi.org/10.26656/fr.2017.6(1).511

\section{Introduction}

Peanuts and cereal crops such as rice, maize, and wheat are extensively propagated and used directly or indirectly as human food, poultry, and animal feeds worldwide. According to a press release for the global peanut market 2019, peanut production and consumption has increased from $413.11 \mathrm{Mt}$ to $450.32 \mathrm{Mt}$ (MarketWatch, 2019). On the other hand, the global consumption of cereals was about 2.6 billion tons in 2017, and this value is projected to increase to about 2.9 billion tons by 2027 due to an increase in food use by $151 \mathrm{Mt}$ and feed use by $167 \mathrm{Mt}$ worldwide (OECD/FAO, 2018). Rice, maize, and wheat were reported as the most consumed cereals. Their global consumption is projected to increase by $1.1 \%$ p.a, $1.3 \%$ p.a, and $15 \%$ p.a, respectively, in 2027, with Asian countries accounting for more than $70 \%$ of the increase in rice consumption (OECD/FAO, 2018).

However, these crops are highly susceptible to fungal attacks both in the field and during storage. In addition, various mould fungi in soil and plant debris produce different kinds of spores (Fillinger et al., 2002; Ogunleye and Olaiya, 2015; Stanić, 2016) that aid in their survival and dissemination, by wind currents, rain, and insects, to various environments and consequently contaminate various crops both before or after harvesting (Chelkowski and Visconti, 1992), leading to foodborne infection, intoxication and deterioration that can result in severe economic losses and health effects to both humans and animals (Gathumbi, 1993; Bhat and 
Vasanthi, 2003; Monge et al., 2013; Rashid et al., 2013). Globally, several outbreaks of human mycotoxicosis have been reported from many countries such as India (Reddy and Raghavender, 2007), Kenya (Yard et al., 2013), Malaysia (Chao et al., 1991), Nigeria (Oyelami et al., 1997) and Thailand (Shank et al., 1971). Recently, two outbreaks of human mycotoxicosis occurred in 2016 in Uganda and Tanzania, with case fatality rates of $30 \%$ out of 68 patients (Kamala et al., 2018) and 75\% of 4 patients (Musewa et al., 2016), respectively.

Several fungi have been identified to contaminate various agricultural products with their toxic secondary metabolites, mycotoxins (Pierron et al., 2016; Wolde, 2017; Singh and Cotty, 2019). However, mould fungi of the species Aspergillus section Flavi (Aspergillus flavus, Aspergillus parasiticus, and Aspergillus nominus) are the most economically important toxigenic fungi that commonly contaminate stored foods with aflatoxins (Kumar et al., 2008; Reddy et al., 2009; Reddy et al., 2010; Uhlig et al., 2013; Oliveira et al., 2017), the most toxic mycotoxins (Habib et al., 2015; Haruna et al., 2017). Furthermore, it has been shown that many foods that were not contaminated before harvesting may become contaminated with these aflatoxigenic fungi and subsequently aflatoxins during storage, especially in high humidity areas (Linda et al., 2019). Hence, the presence of these fungi in foods signifies a tremendous public health threat as their toxic metabolites (aflatoxins) are hepatotoxic, hepatocarcinogenic, teratogenic, nephrotoxic, immunotoxic, and enterotoxic to humans. Thus, the need for continuous screening of foods for these fungi is imperative; hence, the present research is aimed to determine bioburden and morphological characterisation of mycotoxigenic fungi contaminating commonly consumed cereals (rice, wheat, and maize) and peanuts in Kelantan, Malaysia. It is hypothesised that grains in Malaysia contain a significantly high concentration of mycotoxigenic fungi and mycotoxins (Hejri et al., 2013), given that the accumulation of mycotoxins is directly proportional to humidity. As we know, this is the first report of fungal flora contamination of commonly consumed food grains and peanuts in Kelantan, Malaysia.

\section{Materials and methods}

\subsection{Sample collection and preparation}

This study was conducted between June to December 2019. Two open markets (Pasar Siti Khadijah Kota Bharu and Rural Transformation Centre (RTC) Kelantan) found in the study area (Kota Bharu) were selected for this study. A total of 132 food grain samples comprising 33 samples each of maize, wheat, rice, and peanuts were purchased from the selected open markets.
During the sample collection, approximately $500 \mathrm{~g}$ of each food sample was collected in a sterile polythene bag (Shamsuddeen et al., 2017; Salisu et al., 2020), labelled and transported to the laboratory of the School of Health Sciences Universiti Sains Malaysia for analysis. From the 132 samples, a total of 44 composite samples were made, comprising 11 composite samples each of maize, wheat, rice, and peanuts. Each sample was then washed three times with distilled water, dried, ground into crystalline powder using a high-speed blender, transferred into a sterile air-tight container, and stored in a cold room at $4^{\circ} \mathrm{C}$ for further use.

\subsection{Determination of fungal load in each sample}

The total mould fungal count in each sample was determined following the previously reported method (Salisu et al., 2020). For each sample, $10 \mathrm{~g}$ of the powder was homogenised with $90 \mathrm{~mL}$ of Brain Heart Infusion broth, BHIB (Merck 1.10493 Millipore) medium, mixed thoroughly, and a serial dilution $10^{1}$ to $10^{4}$ was then performed in test tubes containing $9 \mathrm{~mL}$ each of sterilised BHIB medium. The test tubes were incubated at $30^{\circ} \mathrm{C}$ for $24 \mathrm{hrs}$ to allow quicker reactivation of fungal spores in the samples. Thereafter, an inoculum of one millilitre $(1 \mathrm{~mL})$ from 3 dilution tubes $\left(10^{2}\right.$ to $\left.10^{4}\right)$ of each sample was pipetted and spread-plated onto sterilised Potato Dextrose Agar, PDA (HIMEDIA, M096) media plates in triplicate each and incubated at $28 \pm 2^{\circ} \mathrm{C}$ for five days. The Plates were observed for mould colonies on day three and day five. The total colony-forming units (CFU) per gram of each sample was determined from the average number of various mould colonies that developed from the PDA plates of the sample as follows:

Total CFU per gram of sample $=$ Mean \pm Standard deviation of CFU/g of the 3 replicates

While $\mathrm{CFU} / \mathrm{g}$ of each replicate $=\mathrm{CFU}$ per $\mathrm{mL} \times \mathrm{V}_{\text {stock }}$ $(\mathrm{mL})$

Where $\mathrm{CFU} / \mathrm{mL}=$ Total CFU per plate $\times$ dilution factor of the inoculum and $\mathrm{V}_{\text {stock }}=$ initial volume used to dissolve one gram of the powdered sample $=9 \mathrm{~mL}$

\subsection{Identification of the fungal isolates}

Various mould colonies from the PDA plates of each sample were separately sub-cultured on Sabouraud Dextrose agar, SDA (HIMEDIA, M063) media plates, and incubated in an upright position at $28 \pm 2^{\circ} \mathrm{C}$ for 3 to 5 days to obtain pure isolates in each sample. Additionally, isolates presumably considered members of the Aspergillus section Flavi were sub-cultured on Aspergillus differential medium (AFPA: "Aspergillus flavus and Aspergillus parasiticus differential medium") 
plates for further phenotypic characterisation. Thereafter, each isolate was subjected to slide culture. Colonies attached to the coverslip from the slide culture plates were stained with lactophenol cotton blue stain, observed under a microscope at $\times 10$ and then $\times 40$ objective magnifications. Finally, the isolates were identified based on their microscopic characteristics such as hyphal types and arrangements, nature of the conidiophore vesicle, conidia heads, ornamentation, phialides, and fruiting body, and their macroscopic or cultural appearances on SDA and AFPA such as colonies colours, texture, reverse colour, hyphae arrangement, conidia shape and nature of spores as previously described elsewhere (Watanabe, 2002; Ellis et al., 2007; Leboffe and Pierce, 2011; Omar-Zahid, 2013; Kidd et al., 2016; Gordon and Julie, 2018; Noman et al., 2018).

\subsection{Statistical analysis}

Version 24 of IBM SPSS statistical software was used to analyse the results. Descriptive statistics were used to summarise the level of contamination of the food grains and peanut samples by mycotoxigenic fungi. Comparing levels of contamination within and between sample categories was performed using one-way ANOVA.

\section{Results}

\subsection{Bioburden of moulds in the samples}

The result of fungal counts in the various samples analysed showed that $100 \%, 90.9 \%$ (10 samples), $63.6 \%$ (7 samples), and $81.8 \%$ (9 samples) of the peanuts, maize, rice, and wheat samples were respectively contaminated by at least one or more species of mould fungi. Twelve different fungal colony types were obtained from the 44 composite food samples analysed. The isolates had multiple occurrences and were heterogeneously distributed in the samples with a total frequency of isolation of 115 . The distribution and frequency of occurrence of all the isolates in each food category are shown in Figure 1. The wheat samples were contaminated by 10 fungal species, followed by the maize and rice, which were contaminated by 8 species each. Although all the peanut samples were contaminated by at least one or more fungi, the contamination was accounted for by only 7 out of the 12 fungal species isolated.

Across all samples, the average contamination level is between $2 \times 10^{3}$ to $6.0 \times 10^{6} \mathrm{CFI} / \mathrm{g}$. Peanuts were found to have the highest fungal count on average $\left(9.7 \times 10^{5} \pm\right.$ $1.5 \times 10^{5} \mathrm{CFU} / \mathrm{g}$ ). This is followed, in decreasing order, by maize $\left(7.5 \times 10^{5} \pm 1.8 \times 10^{6} \mathrm{CFU} / \mathrm{g}\right)$, wheat $\left(1.9 \times 10^{5} \pm\right.$ $\left.2.6 \times 10^{5} \mathrm{CFU} / \mathrm{g}\right)$, and rice $\left(9.9 \times 10^{4} \pm 1.5 \times 10^{5} \mathrm{CFU} / \mathrm{g}\right)$ (Table 1). However, there is no significant difference $(p>0.05)$ between the level of contamination of peanuts and maize or wheat and vice versa. There is also no significant difference $(\mathrm{p}>0.05)$ between the fungal counts in rice and wheat or maize. Conversely, there is a significant difference $(\mathrm{p}<0.05)$ between the level of contamination of peanut and rice.

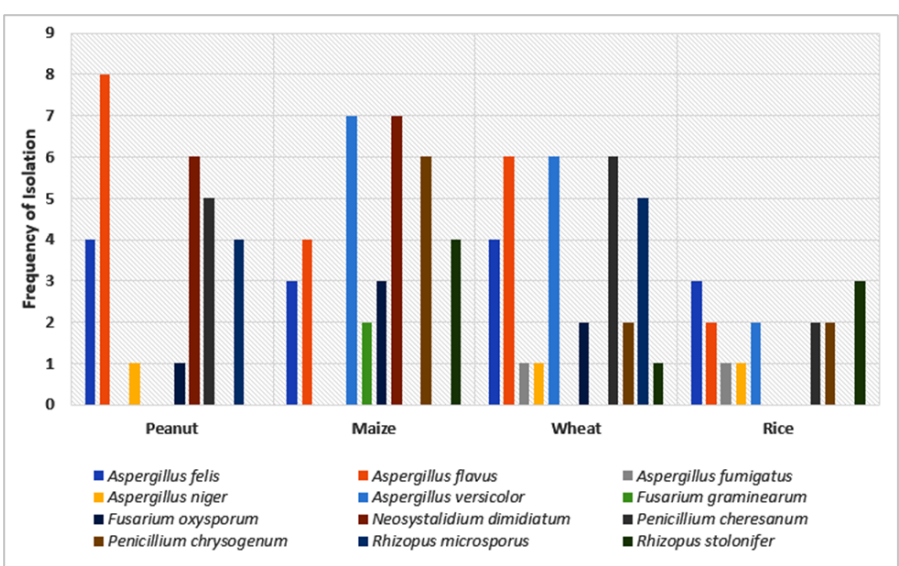

Figure 1. Distribution of the fungal isolates in the cereals and peanut samples

Table 1. Summary of bioburden of filamentous fungi in the peanuts and food grains from Kelantan state, Malaysia

\begin{tabular}{ccccc}
\hline \multirow{2}{*}{ Statistics } & \multicolumn{4}{c}{ Samples } \\
\cline { 2 - 5 } & Peanut & Maize & Rice & Wheat \\
\hline Sample Size (N) & 11 & 11 & 11 & 11 \\
No of Fungal Isolates & 29 & 36 & 16 & 34 \\
Obtained (N = 115) & & & & \\
Mean (CFU/g) & $9.7 \times 10^{5}$ & $7.5 \times 10^{5}$ & $9.9 \times 10^{4}$ & $1.9 \times 10^{5}$ \\
Median & $3.0 \times 10^{5}$ & $2.0 \times 10^{5}$ & $2.0 \times 10^{3}$ & $4.1 \times 10^{4}$ \\
S.D & $1.5 \times 10^{6}$ & $1.8 \times 10^{6}$ & $1.6 \times 10^{5}$ & $2.6 \times 10^{5}$ \\
SEM & $4.4 \times 10^{5}$ & $5.3 \times 10^{5}$ & $4.7 \times 10^{4}$ & $7.8 \times 10^{4}$ \\
Minimum & $1.2 \times 10^{4}$ & $3.7 \times 10^{4}$ & $2.0 \times 10^{3}$ & $9.0 \times 10^{3}$ \\
Maximum & $4.5 \times 10^{6}$ & $6.0 \times 10^{6}$ & $4.0 \times 10^{5}$ & $7.0 \times 10^{5}$ \\
\hline
\end{tabular}

S.D: Standard deviation, SEM: Standard error of mean.

\subsection{Morphological characterisation of the fungal isolates}

The macroscopic and microscopic characteristics of the 115 fungal isolates obtained from the 44 food samples showed that these isolates belong to 12 different fungal species with variable frequencies of isolation. Of the 115 isolates, $20(17.39 \%)$ were presumed as A.flavus as evidenced by their macroscopy (bright, yellow-green, umbonate colonies with some whitish areal hyphae and white border, and a pale yellow to colourless reverse) and microscopic features (septate hyaline hyphae with long rough conidiophores bearing globose vesicles containing uniseriate or biseriate phialides covering the entire vesicle). All 20 isolates produce aspergillic acid in the AFPA medium. However, 7 out of the 20 were not able to produce sclerotia. The A. flavus were followed, in decreasing order of isolation, by Aspergillus versicolor, having 15 (13.04\%) frequency of isolation and A. felis having $14(12.17 \%)$. Others are $13 \quad(11.30 \%)$ 
Neoscytalidium dimidiatum, 13 (11.30\%) Penicillium cheresanum, 10 (8.70\%) Penicillium chrysogenum, 9 (7.83\%) Rhizopus nigricans, 8 (6.70\%) Rhizopus stolonifer, 6 (5.22\%) Fusarium oxysporum, 3 (2.61\%) A. niger, 2 (1.74\%) Fusarium graminearum and 2 (1.74\%) Aspergillus fumigatus. The detailed morphological characteristics of all the 12 fungal species are summarised in Table 2.

\section{Discussion}

The bioburden and type of mould fungi isolated from the cereals and peanut samples in this study signify great public health risks since most of the species are notable mycotoxin producers while others are notable food spoilage fungi that are involved in the deterioration of foods in their attempt to adapt and survive in the environment. A. flavus produces the most toxic and most carcinogenic mycotoxin, aflatoxin B1 (Bankole and Mabekoje, 2004; Kanora and Maes, 2009; LizárragaPaulín et al., 2012); A. versicolor is a fungus that can cause allergy and it also produces the carcinogenic mycotoxin, sterigmatocystin (Piontek et al., 2016); A. felis causes invasive aspergillosis (Barrs et al., 2013) $N$. dimidiatum causes onychomycosis (Bunyaratavej et al., 2016), some strains of $P$. chrysogenum produce Ochratoxin A (Saleemi et al., 2017); F. graminearum is a notable phytopathogen, and it also produces the mycotoxin, type B trichothecene (Atanasova-Penichon et al., 2018), and A. fumigatus causes aspergillosis in humans and animals (Latgé, 1999).

The average level of contamination in all the foods, except rice, was above the permissible limit of $10^{2} \mathrm{CFU} /$ $\mathrm{g}$ set by the Malaysian Ministry of Health and $10^{2}$ to $10^{5}$ $\mathrm{CFU} / \mathrm{g}$ set by the International Commission for Microbiological Specification for Foods (ICMFS, 2006). This high level of contamination is likely the result of the storage conditions and long-time storage practised by the grain sellers (Norlia et al., 2018). In a recent study on the level of aflatoxin contamination in the peanut value chain in Malaysia, it was observed that peanuts from retailers had lower aflatoxin content than those obtained from manufacturers, while peanuts from importers had no detectable aflatoxin level (Norlia et al., 2018). In addition, the use of poor storage facilities by the grain sellers may also contribute to the higher fungal load observed in the samples. Most traders use non-aerated locked up stores without proper ventilation or airconditioning system, as noted during the sampling process. Coupled with higher relative humidity in Malaysia (Hejri et al., 2013), the stores provide ideal conditions (warm temperature) that promote germination of fungal spores, leading to a high rate of mycofloral contamination of the food grains. The type/nature of the sampling environment (open markets) may also be one of the reasons for the high fungal counts in the samples, as opined by Bankole and Mabekoje (2004), who observed a high level of fungal contamination of meat products sold in Sokoto State (Nigeria) open markets. A similar trend of a high level of fungi contaminating open market products was also previously reported in vended peanut cakes and peanut products from some major Nigerian open markets (Adebesin et al., 2001; Salau et al., 2017).

The genus Aspergillus is one of the large fungal genera containing approximately 250 species, currently divided into seven subgenera, which are further subdivided into various sections containing related species (Gordon and Julie, 2018). The species A. felis and A. fumigatus isolated in this study belonged to the Aspergillus section Fumigati. Fungi belonging to this section are most commonly misidentified due to their overlapping morphological characteristics (Gordon and Julie, 2018). This study confirmed the A. felis isolates based on their very short columnar uniseriate conidial heads. In contrast, the A. fumigatus species were confirmed based on their thermotolerance, capable of exhibiting good growth at $48^{\circ} \mathrm{C}$ and up to $55^{\circ} \mathrm{C}$, differentiating them from other Aspergillus species (Kidd et al., 2016). Three other Aspergillus spp isolated in this study are A.flavus, A. niger, and $A$. versicolor, belonging to Aspergillus section Flavi, Nigri, and Versicolores, respectively. Microscopically, A. flavus is often confused with A. fumigatus and some other Aspergillus spp; however, A. flavus produces globose vesicle while $A$. fumigatus produces flask-shaped vesicles (Gordon and Julie, 2018). Besides, A. flavus possesses rough-walled stipe and radial conidial heads, which further distinguish it from other Aspergillus spp (Kidd et al., 2016). Although sclerotia is an important feature that is used in classifying A. flavus into $\mathrm{S}$ and $\mathrm{L}$ strains, 7 out of the 20 A. flavus isolated in this study do not produce sclerotia; but they all produce aspergillic acid in AFPA medium, and they have the distal rough-walled conidiophore which is a peculiar feature of A. flavus. Aspergillus niger has a potential look-alike with the Syncephalastrum racemosum (Gordon and Julie, 2018). Still, the former can be easily distinguished from the later based on its white to yellow colonies, which later become covered by a dense layer of brown to black conidial heads, and microscopically, its conidiophores are hyaline or pale brown, long, non-branched and thick-walled bearing radiate dark-brown conidial heads (Watanabe, 2002). Aspergillus versicolor has a similar appearance with some Penicillium spp, especially Penicillium marneffei (now known as Talaromyces marneffei); however, the former has vesicles covered by biseriate phialides while the latter has no vesicle, but only a cluster of phialides 
Table 2. Morphological characterisation of the fungal isolates and their frequency of isolation in the food samples

\begin{tabular}{|c|c|c|c|c|c|}
\hline \multirow{2}{*}{ No } & \multicolumn{2}{|c|}{ Morphological Characteristics of the Isolates } & \multirow{2}{*}{ Name of Isolate } & \multicolumn{2}{|c|}{ Frequency of Isolation } \\
\hline & Macroscopy & Microscopy & & $\mathrm{n}$ & $\%$ \\
\hline 1 & $\begin{array}{l}\text { Bluish green colonies with milk } \\
\text { fluffy surface and milk reverse side. }\end{array}$ & $\begin{array}{l}\text { Hyaline, septate, branched hyphae } \\
\text { with uniseriate and columnar } \\
\text { conidial heads with the phialides } \\
\text { limited to the upper two-thirds of } \\
\text { the vesicle and curving to be } \\
\text { roughly parallel to each other. }\end{array}$ & Aspergillus felis & 14 & 12.17 \\
\hline 2 & $\begin{array}{l}\text { Bright, yellow-green, umbonate } \\
\text { colonies with whitish areal hyphae } \\
\text { and white border, and a pale yellow } \\
\text { to milk reverse side }\end{array}$ & $\begin{array}{l}\text { Septate hyaline hyphae with long } \\
\text { rough conidiophores bearing } \\
\text { globose vesicles containing } \\
\text { uniseriate or biseriate phialides } \\
\text { covering the entire vesicle }\end{array}$ & $\begin{array}{l}\text { Aspergillus } \\
\text { flavus }\end{array}$ & 20 & 17.39 \\
\hline
\end{tabular}

Bluish Green umbonate colonies 3 with whitish areal hyphae and white -grey border, and a pale yellow to milk reverse side

Downy white to yellow umbonate colonies with dark brown to black pinpoints and white border, with milk to a pale yellow reverse side

Greenish ash suede-like colonies with radial grooves and some reddish colorations (exudate) with the reddish-brown reverse side

Septate hyaline hyphae with long conidiophores bearing flask-shaped vesicles containing uniseriate or biseriate phialides covering the Aspergillus fumigatus 2 upper third of the vesicle

Branched septate hyaline hyphae with long smooth conidiophores bearing large globose vesicles surrounded by radiate biseriate phialides

Septate hyphae with long rough conidiophores bearing thick-walled

6 Dark pink cottony colonies with pinkish reverse sides

Cottony, velvety colonies with pink

7 in centre and white border with a pale brown reverse side

Milk umbonate colonies with a

9 cottony periphery and a pale-yellow reverse side

Cottony white growth with a pale yellow to greyish reverse side spherical conidia, small globose vesicles with biseriate phialides covering the upper third of the vesicles

Branched septate hyphae bearing multicellular septate macroconidia having 3 septum and aseptate microconidia.

Branched septate hyphae bearing multicellular spindle-like septate conidia. No microconidia were seen.

Branched and septate hyphae with

no conidiophores. Arthroconidia are rectangular and flattened on the ends.

Hyaline septate hyphae bearing simple conidiophores that support multiple chains of single-celled

conidia

Aspergillus

versicolor with numerous conidiophores bearing brush-like clusters of phialides that bear chains of conidia Rhizoid-borne, long, unbranched brownish sporangiophores bearing round greyish-black sporangia with round columellae.

Fusarium

oxysporum

6

\section{Fusarium}

graminearum

2

Neoscytalidium

dimidiatum

Penicillium

cheresanum
Penicillium

chrysogenum

Rhizopus

microsporus
Blue-green umbonate colonies with yellowish pigment and milk border with a pale-yellow reverse side

Blueish green and umbonate

11 colonies with wide milk border and a pale-yellow reverse side
Rhizoid-borne, long, unbranched sporangiophores bearing round black sporangia with round
Rhizopus stolonifer

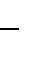


arranged in open or divergent penicillus formation (Gordon and Julie, 2018).

Two types of Fusarium spp. (Fusarium graminearum and $F$. oxysporum) were isolated from this study's samples. Both $F$. graminearum and $F$. oxysporum produce long curved macroconidia like Acrimonium spp; however, the former differs from the latter by the woolly surface texture of their colonies (Gordon and Julie, 2018). Fusarium graminearum differs from other Fusarium spp by its unique slightly curved, short, wide macroconidia with four to five septa, and it does not produce microconidia (Pitt, 2014). On the other hand, $F$. oxysporum differs from other Fusarium spp by having numerous non-septate microconidia and abundant chlamydospores (Gordon and Julie, 2018). It is noteworthy that the $F$. oxysporum isolates obtained from the samples in this study produce few chlamydospores; thus, only the non-septate microconidia confirm their identity. Three other woolly moulds isolated in this study are Neoscytalidium dimidiatum, Rhizopus microsporus, and Rhizopus stolonifer, all of which grow rapidly, filling the entire plate. However, these species are easy to identify based on their remarkable peculiar microscopic features. Neoscytalidium dimidiatum possess branched septate hyphae with many blocky arthroconidia (Kidd et al., 2016), R. microsporus differ from other Rhizopus spp by its thermotolerance (capable of growing at $45^{\circ} \mathrm{C}$ and up to $52^{\circ} \mathrm{C}$ ), $R$. stolonifer is like $R$. microsporus, but it cannot grow above $45^{\circ} \mathrm{C}$ (Kidd et al., 2016). Two penicillium spp ( $P$. cheresanum and $P$. chrysogenum) were also isolated in this study. Both have the same appearance as those we isolated from food grains in Nigeria recently (Salisu et al., 2020).

The species of Aspergillus, Rhizopus, and Penicillium recovered from the samples in this study were consistent with previous reports of fungal contamination of foods in Malaysia (Abdullah et al., 1998; Reddy et al., 2011; Samsudin and Abdullah, 2013) who reported these species alongside others which were not isolated in this study as major fungal contaminants of Malaysian foods. However, our result did not agree with that of Samsudin and Abdullah (2013) with respect to the population and prevalence of mycoflora in rice samples. They reported the predominant fungal species contaminating red rice at the consumer level in Selangor (Malaysia) as $P$. chrysogenum (62\%), A. niger (54\%), and $A$. flavus (44\%). In our study, A. felis was the most predominant, followed by A. flavus, $P$. chrysogenum, and others. On the other hand, the overall high prevalence of A. flavus and very low occurrence of $A$. fumigatus observed in this study has agreed with the reports of Abdullah et al. (1998) and Reddy et al. (2011), who reported a similar trend of fungal contamination of
Malaysian foods.

Furthermore, it has been shown that higher water activity in peanuts coupled with warm temperature is ideal for the rapid proliferation of storage fungi, especially A. flavus (Liu et al., 2017). This could explain why the peanut samples in this study have the highest fungal contamination level, especially by $A$. flavus, compared to the other samples with lower water activity. Overall, the fungal species isolated from the food grains and peanuts in this study were consistent with many similar reports by other researchers from different countries such as Nigeria, Lesotho, Malaysia, and Pakistan (Bankole et al., 2004; Mohale and Alloytey, 2011; Samsudin, 2011; Shanakht et al., 2012).

\section{Conclusion}

This study revealed that the peanuts and cereal samples analysed in this study were highly contaminated, above the permissible limit of both Malaysian $\mathrm{MOH}$ and ICMSF, by notable mycotoxigenic fungi, especially members of the Aspergillus section Flavi that are known to produce potent carcinogenic mycotoxins (aflatoxins). Therefore, further studies, especially intervention studies that will assess the level of mycotoxins in the food grains and peanuts, as well as evaluating and improving the level of stakeholders' knowledge, attitude, and practice towards fungal and mycotoxins contamination of peanuts and cereals in the study area and other parts of Malaysia are highly recommended.

\section{Conflicts of interests}

We declare there is no conflict of interest between authors or with others in any aspect.

\section{Acknowledgements}

The authors are grateful to Siti Kurunisa Mohd Hanafiah, Muhammad Syafiq Sidek Ahmad, and the UPMS staff of the School of Health Sciences, Universiti Sains Malaysia, who have been extremely helpful. This study is funded under the Fundamental Research Grant Scheme (FRGS/1/2019/SKK06/USM/03/1), Ministry of Higher Education Malaysia.

\section{References}

Abdullah, N., Nawawi, A. and Othman, I. (1998). Survey of fungal counts and natural occurrence of aflatoxins in Malaysian starch-based foods. Mycopathologia, 143(1), 53-58. https://doi.org/10.1023/ A:1006945514876

Adebesin, A.A., Saromi, O.T., Amusa, N.A. and Fagade, S.O. (2001). Microbiological quality of some 
groundnut products hawked in Bauchi, a Nigerian City, Journal of Food Technology in Africa, 6(2), 53 -55. https://doi.org/ 10.4314/jfta.v6i2.19287

Atanasova-Penichon, V., Legoahec, L., Bernillon, S., Deborde, C., Maucourt, M., Verdal-Bonnin, M.N., Pinson-Gadais, L., Ponts, N., Moing, A. and Richard -Forget, F. (2018). Mycotoxin biosynthesis and central metabolism are two interlinked pathways in Fusarium graminearum, as demonstrated by the extensive metabolic changes induced by caffeic acid exposure. Applied and Environmental Microbiology, 84(8). https://doi.org/10.1128/AEM.01705-17

Bankole, S.A. and Mabekoje, O.O. (2004). Mycoflora and occurrence of aflatoxin B1 in dried yam chips from markets in Ogun and Oyo States, Nigeria. Mycopathologia, 157(1), 111-115. https:// doi.org/10.1023/B:MYCO.0000012211.31618.18

Bankole, S.A., Ogunsanwo, B.M. and Mabekoje, O.O. (2004). Natural occurrence of moulds and aflatoxin B1 in melon seeds from markets in Nigeria. Food and Chemical Toxicology, 42(8), 1309-1314. https:// doi.org/10.1016/j.fct.2004.03.015

Barrs, V.R., van Doorn, T.M., Houbraken, J., Kidd, S.E., Martin, P., Pinheiro, M.D., Richardson, M., Varga, J. and Samson, R.A. (2013). Aspergillus felis sp. nov., an emerging agent of invasive aspergillosis in humans, cats, and dogs. PLoS ONE, 8(6), e64871. https://doi.org/10.1371/journal.pone.0064871

Bhat, R.V. and Vasanthi, S. (2003). Mycotoxin food safety risk in developing countries. Food Safety in Food Security and Food Trade, 3(17), 1-2.

Bunyaratavej, S., Leeyaphan, C., Rujitharanawong, C., Surawan, T.M., Muanprasat, C. and Matthapan, L. (2016). Efficacy of 5\% amorolfine nail lacquer in Neoscytalidium dimidiatum onychomycosis. Journal of Dermatological Treatment, 27(4), 359-363. https://doi.org/10.3109/09546634.2015.1109029

Chao, T.-C., Maxwell, S.M. and Wong, S.-Y. (1991). An outbreak of aflatoxicosis and boric acid poisoning in Malaysia: A clinicopathological study, The Journal of Pathology, 164(3), 225-233. https:// doi.org/10.1002/path.1711640307

Chelkowski, J. and Visconti, A. (1992). Alternaria: biology, plant diseases, and metabolites, p. 573. New York, USA: Elsevier.

Ellis, D., Davis, S., Alexiou, H., Handke, R. and Bartley, R. (2007). Descriptions of medical fungi. $2^{\text {nd }}$ ed. Retrieved June 12, 2020 from www.mycology.adelaide.edu.au

Fillinger, S., Marie-Kim, C., Kiminori, S., Keller, N. and D'Enfert, C. (2002). cAMP and ras signalling independently control spore germination in the filamentous fungus Aspergillus nidulans. Molecular
Microbiology,

44(4),

$1001-1016$.

https:// doi.org/10.1046/j.1365-2958.2002.02933.x

Gathumbi, K. (1993). A survey of mycotoxigenic fungi and mycotoxins in poultry feed. University of Nairobi. Retrieved June 14, 2020 from http:// erepository.uonbi.ac.ke/handle/11295/21051

Gordon, L.L. and Julie, A.R. (2018). Colour atlas of mycology- an illustrated field guide based on proficiency testing. Northfield, Illinois, USA: College of American Pathologists.

Habib, M.A., Abdu, P., Kwanashie, C.N., Kabir, J. and Negedu, A. (2015). Isolation and identification of Aspergillus species from poultry feeds in Kaduna State, Nigeria. Microbiology Research International, 3(2), 27-32.

Haruna, M., Dangora D.B., Khan, A.U., Batagarawa, U.S.B. and Ibrahim, H. (2017). Incidence of fungal Flora and Aflatoxin in Some Spices Sold in Central Market, Funtua, Nigeria. UMYU Journal of Microbiology Research, 2(1), 47-53.

Hejri, L.A., Jinap, S., Hajeb, P., Radu, S. and Shakibazadeh, S. (2013). A review on mycotoxins in food and feed: Malaysia case study. Comprehensive Reviews in Food Science and Food Safety, 12(6), 629-651. https://doi.org/10.1111/1541-4337.12029

ICMFS. (2006). Microorganisms in Foods 6: Microbial Ecology of Food Commodities. In Microorganisms in Foods 6: Microbial Ecology of Food Commodities. $6^{\text {th }}$ ed. Netherlands: Kluwer Academic/Plenum Publishers. https:// doi.org/10.1007/0-387-28801-5

Kamala, A., Shirima, C., Jani, B., Bakari, M., Sillo, H., Rusibamayila, N., De Saeger, S., Kimanya, M., Gong, Y.Y. and Simba, A. (2018). Outbreak of an acute aflatoxicosis in Tanzania during 2016, World Mycotoxin Journal, 11(3), 311-320. https://doi.org/ 10.3920/WMJ2018.2344

Kanora, A. and Maes, D. (2009). The role of mycotoxins in pig reproduction: a review. Veterinarni Medicina, 2009(12), 565-576. https:// doi.org/10.17221/156/2009-VETMED

Kidd, S., Halliday, C., Alexiou, H. and Ellis, D. (2016). Descriptions of medical fungi. $3^{\text {rd }}$ ed. Retrieved June 12, 2020 from www.mycology.adelaide.edu.au

Kumar, V., Basu, M.S. and Rajendran, T.P. (2008). Mycotoxin research and mycoflora in some commercially important agricultural commodities. Crop Protection, 27(6), 891-905. https:// doi.org/10.1016/j.cropro.2007.12.011

Latgé, J.P. (1999). Aspergillus fumigatus and aspergillosis. Clinical Microbiology Reviews, 12(2), 310-350. https://doi.org/10.1128/cmr.12.2.310

Leboffe, J.M. and Pierce, B.E. (2011). A Photography 
Atlas for the Microbiology Laboratory. $4^{\text {th }}$ Ed. Colorado, USA: Morton Publishing. http:// www.uobabylon.edu.iq/eprints/ publication_12_24710_198.pdf

Linda, G.M., Arnold B.M., Leslie, M. and Author, C. (2019). Effect of drying techniques and storage conditions on quality and incidence of aflatoxins in dried chillies (Capsicum frutescens) in Zimbabwe, Acta Scientific Agriculture, 3(7), 21-25. https:// doi.org/10.31080/ASAG.2019.03.0511

Liu, X., Guan, X., Xing, F., Lv, C., Dai, X. and Liu, Y. (2017). Effect of water activity and temperature on the growth of Aspergillus flavus, the expression of aflatoxin biosynthetic genes and aflatoxin production in shelled peanuts. Food Control, 82, 325-332. https://doi.org/10.1016/j.foodcont.2017.07.012

Lizárraga-Paulín, E.G., Moreno-Martínez, E. and Miranda-Castro, S.P. (2012). Aflatoxins and their impact on human and animal health: an emerging problem. In Guevara-Gonzalez, R.G. (Ed.) Aflatoxins - Biochemistry and Molecular Biology, p. 255-282. InTech Open E-Book. https:// doi.org/10.5772/26196

MarketWatch. (2019). Global Peanuts Market 2019 Global Industry Size Analyzed by Business Opportunity, Development, Growth Factors, Applications Analysis and Future Prospects 2024 MarketWatch. Retrieved August 21, 2020 from https://www.marketwatch.com/press-release/globalpeanuts-market-2019-global-industry-size-analyzedby-business-opportunity-development-growthfactors-applications-analysis-and-future-prospects2024-2019-07-23

Mohale, S. and Alloytey, J. (2011). Mould contamination of ready-to-eat cereal-based foods retailed in lesotho with special reference to toxigenic Aspergillus flavus. African Journal of Food Agriculture Nutrition and Development, 11(6), 5318-5334.

Monge, M.P., Dalcero, A.M., Magnoli, C.E. and Chiacchiera, S.M. (2013). Natural co-occurrence of fungi and mycotoxins in poultry feeds from Entre Ríos, Argentina. Food Additives and Contaminants: Part B Surveillance, 6(3), 168-174. https:// doi.org/10.1080/19393210.2013.777946

Musewa, A., Namayanja, J., Tumwine, G., Tuhebwe, D., Naigaga, I., Buregyeya, E. and Nsamba, P. (2016) One Health Approach Towards Management of an Aflatoxicosis Outbreak in Bukomansimbi District. Retrieved July 16, 2020 from https://pmac2018.com/ uploads/poster/B05-MUSEWA-aa58.pdf

Noman, E.A., Al-gheethi, A.A., Hideyuki, N., Maya, R., Radin, S., Division, E.E. and Pahat, B. (2018). Phenotypic identification of Penicillium spp isolated from clinical wastes based on microstructure characteristics. Malaysian Journal of Microbiology, 14(3), 88-95. https://doi.org/10.21161/mjm.27918

Norlia, M., Nor-Khaizura, M. A.R., Selamat, J., Abu Bakar, F., Radu, S., Cheow, and Chin, K. (2018). Evaluation of aflatoxin and Aspergillus sp. contamination in raw peanuts and peanut-based products along this supply chain in Malaysia. Food Additives and Contaminants: Part A, 35(9), 17871802.

https:// doi.org/10.1080/19440049.2018.1488276

OECD/FAO. (2018). Cereals. In OECD-FAO Agricultural Outlook 2018-2027. $4^{\text {th }}$ ed., p. 109-264. OECD Publishing. https://doi.org/10.1787/agr-outldata-en

Ogunleye, A.O. and Olaiya, G.A. (2015). Isolation, identification, and mycotoxin production of some mycoflora of dried stockfish (Gadus morhua). Academic Journal of Science, 4(1), 345-363.

Oliveira, M.S., Rocha, A., Sulyok, M., Krska, R. and Mallmann, C.A. (2017). Natural mycotoxin contamination of maize (Zea mays L.) in the South region of Brazil. Food Control, 73(Part B), 127-132. https://doi.org/10.1016/j.foodcont.2016.07.033

Omar-Zahid, L.A. (2013). Atlas of Food Microbiology LAB. 1st ed. Israel: University of Baghdad - College of Science - Department of Biology.

Oyelami, O.A., Maxwell, S.M., Adelusola, K.A., Aladekoma, T.A. and Oyelese, A.O. (1997). Aflatoxins in the lungs of children with kwashiorkor and children with miscellaneous diseases in Nigeria, Journal of Toxicology and Environmental Health, 51 (6), 623-628. https:// doi.org/10.1080/00984109708984048

Pierron, A., Mimoun, S., Murate, L.S., Loiseau, N., Lippi, Y., Bracarense, A.-P.F.L., Liaubet, L., Schatzmayr, G., Berthiller, F., Moll, W.-D. and Oswald, I.P. (2016). Intestinal toxicity of the masked mycotoxin deoxynivalenol-3- $\beta$-d-glucoside. Archives of Toxicology, 90(8), 2037-2046. https:// doi.org/10.1007/s00204-015-1592-8

Piontek, M., Łuszczyińska, K. and Lechów, H. (2016). Occurrence of the toxin-producing Aspergillus versicolor tiraboschi in residential buildings. International Journal of Environmental Research and Public Health, 13(9), 862. https:// doi.org/10.3390/ijerph13090862

Pitt, J.I. (2014). Mycotoxins Deoxynivalenol and Other Trichothecenes. In Motarjemi, Y. (Eds). Encyclopedia of Food Safety, p. 295-298. USA: Academic Press. https://doi.org/10.1016/B978-0-12378612-8.00193-1

Rashid, N., Bajwa, M.A., Rafeeq, M., Tariq, M.M., 
Abbas, F., Awan, M.A., Khan, M.A., Shahzad, I., Rehman, A. and Ahmad, Z. (2013). Prevalence of aflatoxicosis in broiler chickens in Quetta, Pakistan. Pakistan Journal of Zoology, 45(4), 1021-1026.

Reddy, B.N. and Raghavender, C.R. (2007). Outbreaks of aflatoxicosis in India. African Journal of Food Agriculture Nutrition and Development, 7, 1-17. https://doi.org/ 10.1016/0370-2693(91)90786-P.

Reddy, K.R.N., Abbas, H.K., Abel, C.A., Shier, W.T., Oliveira, C.A.F. and Raghavender, C.R. (2009). Mycotoxin contamination of commercially important agricultural commodities. Toxin Reviews, 28(2-3), 154-168. https:// doi.org/10.1080/15569540903092050

Reddy, K.R.N., Farhana, N.I. and Salleh, B. (2011). Occurrence of Aspergillus spp and aflatoxin B1 in Malaysian foods used for human consumption. Journal of Food Science, 76(4), T99-T104. https:// doi.org/10.1111/j.1750-3841.2011.02133.x

Reddy, K.R.N., Salleh, B., Saad, B., Abbas, H.K., Abel, C.A. and Shier, W.T. (2010). An overview of mycotoxin contamination in foods and its implications for human health. Toxin Reviews, 29(1), 3-26. https://doi.org/10.3109/15569541003598553

Salau, A.I., Shehu, K. and Kasarawa, A.B. (2017). Morphological Characterization of Mycotoxigenic Fungi Contaminating Groundnut Products in Sokoto State. International Journal of Research in Pharmacy and Biosciences, 4(4), 1-7.

Saleemi, M.K., Zargham Khan, M., Khan, A., Hameed, M.R., Khatoon, A., Ul Abdin, Z., Zahoor, A. and Hassan, Z.U. (2017). Study of fungi and their toxigenic potential isolated from wheat and wheat bran. Toxin Reviews, 36(1), 80-88. https:// doi.org/10.1080/15569543.2016.1233890

Salisu, B., Anua, S.M., Wan Ishak, W.R. and Lawal, U. (2020). Incidence, distribution and phenotypic characterisation of aflatoxigenic fungi contaminating commonly consumed food grains in Katsina State, Nigeria. Malaysian Journal of Medicine and Health Sciences, 16(Supp11), 18-27.

Samsudin, N.I.P. (2011). Mycotoxigenic fungi and mycotoxins contaminating red rice at consumer level in Selangor. Malaysia: University of Malaya Kuala Lumpur, PhD. Dissertation.

Samsudin, N.I.P. and Abdullah, N. (2013). A preliminary survey on the occurrence of mycotoxigenic fungi and mycotoxins contaminating red rice at consumer level in Selangor, Malaysia. Mycotoxin Research, 29(2), 89-96. https://doi.org/10.1007/s12550-012-0154-7

Shamsuddeen, U., Ahmad, M.A. and Abdulkadir, R.S. (2017). Evaluation of Aflatoxin Contamination in Zea mays (Maize) Sold in Katsina. UMYU Journal of
Microbiology Research (UJMR), 2(1), 102-106.

Shanakht, H., Ali, S.A. and Waseem, A.S. (2012). Characterization of fungal microbiota on rice grains from local markets of Lahore. Journal of Hygienic Engineering and Design, 9, 35-40.

Shank, R.C., Bourgeois, C.H., Keschamras, N. and Chandavimol, P. (1971). Aflatoxins in autopsy specimens from Thai children with an acute disease of unknown aetiology. Food and Cosmetics Toxicology, 9(4), 501-507. https://doi.org/ 10.1016/0015-6264(71)90080-0

Singh, P. and Cotty, P.J. (2019). Characterization of Aspergilli from dried red chilies (Capsicum spp.): Insights into the etiology of aflatoxin contamination. International Journal of Food Microbiology, 289, 145-153. https://doi.org/10.1016/ j.ijfoodmicro.2018.08.025

Stanić, A. (2016). Preparation of thiol conjugates of the mycotoxin deoxynivalenol and their occurrence in nature. Oslo: University of Oslo, $\mathrm{PhD}$. Thesis.

Uhlig, S., Eriksen, G., Hofgaard, I.S., Krska, R., Beltrán, E. and Sulyok, M. (2013). faces of a changing climate: semi-quantitative multi-mycotoxin analysis of grain grown in exceptional climatic conditions in Norway. Toxins, 5(10), 1682-1697. https:// doi.org/10.3390/toxins5101682

Watanabe, T. (2002). Soil and seed fungi. $2^{\text {nd }}$ ed. USA: CRC Press. https://doi.org/10.1017/ s0953756202216925

Wolde, M. (2017). Effects of aflatoxin contamination of grains in Ethiopia. International Journal of Agricultural Sciences,7(4), 1298-1307. www.internationalscholarsjournals.org

Yard, E.E., Daniel, Johnni, H., Lewis, L.S., Rybak, M.E., Paliakov, E.M., Kim, A.A., Montgomery, J.M., Bunnell, R., Abudo, M.U., Akhwale, W., Breiman, R.F. and Sharif, S.K. (2013). Human aflatoxin exposure in Kenya, 2007: a cross-sectional study. Food Additives and Contaminants, Part A, 30(7), 1322-1331. https://doi.org/ $10.1080 / 19440049.2013 .789558$ 